\title{
Effects of Cardiac Rehabilitation Exercise Protocols on Physical Function in Patients with Chronic Heart Failure: An Experience from a Resource Constraint Nation
}

\author{
Taofeek O. Awotidebe ${ }^{*}$, Rufus A. Adedoyin1, Michael O. Balogun ${ }^{2,3}$, \\ Rasaq A. Adebayo ${ }^{2,3}$, Victor O. Adeyeye ${ }^{3}$, Kayode I. Oke ${ }^{4}$, Rita N. Ativie5, \\ Anthony 0. Akintomide ${ }^{2,3}$, Mukadas 0. Akindele ${ }^{6}$ \\ ${ }^{1}$ Department of Medical Rehabilitation, College of Health Sciences, Obafemi Awolowo University, \\ Ile-Ife, Nigeria \\ ${ }^{2}$ Department of Medicine, College of Health Sciences, Obafemi Awolowo University, Ile-Ife, Nigeria \\ ${ }^{3}$ Cardiac Care Unit, Obafemi Awolowo University Teaching Hospitals Complex, Ile-Ife, Nigeria \\ ${ }^{4}$ Department of Physiotherapy, School of Medical Sciences, University of Benin, Benin, Nigeria \\ ${ }^{5}$ Department of Medical Rehabilitation, College of Health Sciences and Technology, University of Nigeria, \\ Enugu Campus, Enugu, Nigeria \\ ${ }^{6}$ Department of Physiotherapy, College of Allied Health Sciences, Bayero University Kano, Kano State, Nigeria \\ Email: *tidebet@yahoo.com
}

Received 8 July 2016; accepted 14 August 2016; published 17 August 2016

Copyright (C) 2016 by authors and Scientific Research Publishing Inc.

This work is licensed under the Creative Commons Attribution International License (CC BY).

http://creativecommons.org/licenses/by/4.0/

(c) (i) Open Access

\begin{abstract}
Objective: This study investigated the effects of cardiac rehabilitation exercise protocols on physical function (PF) in patients with chronic heart failure (CHF). Study Design and Setting: This randomized controlled trial recruited 70 patients who are in stage II CHF with ejection fraction $(\mathbf{4 0 \%}$ ) from a Nigerian university teaching hospital. They were randomly assigned into Exercise Group (EG: $n=35$ ) or Control Group (CG: $n=35$ ). Physical function, activity of daily living (ADL), distance walked in six minutes and grip strength were assessed using a validated ADL questionnaire, six minute walk test and a hand dynamometer respectively. In addition to medication, EG underwent aerobic and upper extremity resistance exercises thrice weekly for eight weeks while CG used medications only. Data were analyzed using descriptive and inferential statistics. Alpha level was at $p<0.05$. Results: EG and CG were comparable in age and physical characteristics. Physical function and cardiovascular parameters were comparable at baseline $(p>0.05)$. Significant improvements were noticed at fourth week among participants' ADL $(30.0 \% \pm 6.0 \%), 6 \mathrm{MWD}$ $(321.7 \pm 26.3 \mathrm{~m})$ and $\mathrm{VO}_{2} \mathrm{max}(8.9 \pm 0.4 \mathrm{~mL} / \mathrm{kg} / \mathrm{min})$ variables within the exercise EG but no sig-

*Corresponding author.

How to cite this paper: Awotidebe, T.O., Adedoyin, R.A., Balogun, M.O., Adebayo, R.A., Adeyeye, V.O., Oke, K.I., Ativie, R.N., Akintomide, A.O. and Akindele, M.O. (2016) Effects of Cardiac Rehabilitation Exercise Protocols on Physical Function in Patients with Chronic Heart Failure: An Experience from a Resource Constraint Nation. International Journal of Clinical Medicine, 7, 547-557. http://dx.doi.org/10.4236/ijcm.2016.78060
\end{abstract}


nificant changes were observed in the CG $(p>0.05)$. Participants in EG demonstrated more significant improvements in ADL $(15.0 \% \pm 5.0 \%), 6 \mathrm{MWD}(406.0 \pm 29.7 \mathrm{~m})$ and $\mathrm{VO}_{2} \max (10.3 \pm 0.5$ $\mathrm{mL} / \mathrm{kg} / \mathrm{min})(p<0.05)$ than CG: ADL $(42.0 \% \pm 5.0 \%), 6 \mathrm{MWD}(321.0 \pm 25.7 \mathrm{~m})$ and $\mathrm{VO}_{2} \max (8.9 \pm$ $0.4 \mathrm{~mL} / \mathrm{kg} / \mathrm{min})$ at eighth $(p>0.05)$. Conclusions: Cardiac rehabilitation exercise protocols involving self-paced walking, sit-to-stand and upper extremity dynamic strength training improved activity of daily living, walking and functional capacity in patients with stable chronic heart failure.

\title{
Keywords
}

\author{
Cardiac Rehabilitation Exercise, Physical Function, Heart Failure
}

\section{Introduction}

In the recent time, the prevalence of Chronic Heart Failure (CHF) is on the increase globally [1]. The increasing prevalence has been attributed to rise in aged population, improvement in health and medical services [2]. In sub-Saharan Africa (SSA), the actual prevalence estimate of CHF is not known but hospital admission rate of 3.0\% and 7.0\% has been reported [3]. In addition, two separate studies in Nigeria, Adedoyin and Adesoye [4] and Ojji et al. [5] reported prevalence rates of 3.5\% and 4.3\% respectively.

There are evidence that major advances in pharmacological and device therapies have improved survival rate of patients with CHF; however, many remain burdened with exercise intolerance and disability [6] [7]. Exercise is the central element and the building block for improving physical function such as grasping, transferring, walking capacity that are required for activities of daily living [8] [9]. In turn, improved physical function predicts survival and is associated with significant reduction in hospitalization and all-cause mortality in CHF [10].

Although, there are many exercise regimens in the literature, there is controversy on studies related CHF rehabilitation. A systematic review of literature shows that majority of studies used cycle ergometer or combined exercise programmes including treadmill walk and resistance training or jogging [11]. However, none of the studies attempted to assess patients' acceptance of such exercise protocols and their ability to adopt such procedures on an individual long-term basis that may enhance sustainability and adherence practice [11] [12].

The National Institutes of Health Roadmap Initiative and the Patient Reported Outcomes Measurement Information System (PROMIS) have recommended activities involving mobility (lower extremity), dexterity (upper extremity), axial or central (neck and back function) for optimal physical function [13]. However, exercise protocols involving upper extremity, self-paced walking and trunk muscles activation closely mimic activities of daily living that may be better suited as functional exercises [14]. The appropriate exercise protocols that will serve as the first line of exercise interventions for improving physical function in patients with CHF are still a challenge [15]. For example, exercise prescription including exercise intensity, frequency and duration vary across studies [16]. Furthermore, few studies have explored specific exercise training that is tailored towards improving physical function in patients with CHF. Also, studies investigating the effects of self-paced walk exercise, sit-to-stand and upper extremity resistance training on physical function in patients with CHF are scant.

Cardiac rehabilitation programmes are well established in the developed nations with significant improvement in quality of life and prevention of deconditioning among patients with cardiac problems. Apart from limited resources and experts in the field of cardiac rehabilitation, physician are not routinely referring patients for rehabilitation, because many still have the notion that exercise may exacerbate the cardiac condition. This study was designed and executed jointly with cardiologists with a view of establishing the role of structured exercise in patients with cardiac challenges in developing nations. This study investigated the effects of cardiac rehabilitation exercise including self-paced walking exercise, sit-to-stand and upper extremity resistance training on physical function among patients with CHF.

\section{Methods}

\subsection{Study Sample}

This study was a randomized controlled trial. Participants for this study were patients with chronic heart failure who were attending the medical outpatient, Cardiac Care Unit of the Obafemi Awolowo University Teaching 
Hospitals Complex (OAUTHC), Ile-Ife, Nigeria. Eligibility for participation included patients whose ages were 50 years and older, a clinical diagnosis of CHF, stage II stable CHF using the New York Heart Association (NYHA) functional classification. Furthermore, the Left Ventricular Ejection Fraction (LVEF) was less than $40 \%$ using echo-graphic assessment results obtained by the cardiologists $\left(\mathrm{MOB}^{2}\right.$ and $\left.\mathrm{RAA}^{2}\right)$. Patients who presented with unstable angina pectoris, severe medical conditions and musculoskeletal or neurological disorders limiting participation in exercise were excluded. Furthermore, recent history of participation in exercise programme or patients whose condition may require change of medications during the course of this study were excluded.

The study was carried at a teaching hospital that was founded on integrated comprehensive health-care services based on pyramidal structure designed to secure excellent and efficient health-care services. The institution provides health-care services to more than 10 million Nigerians in South West Zone of Nigeria. The hospital is the first to provide kidney transplant service in the West Africa sub-region and also known as one of the leading hospitals for cardiovascular disease management which covers Ondo, Osun, Oyo, Ekiti, Edo and part of Kwara State [4].

Participants were recruited consecutively using purposive sampling technique and randomly assigned into Exercise Group $(E G)$ (males $=18$, females $=17$ ) or Control Group $(C G)($ males $=14$, females $=21$ ). Randomization was performed by a research assistant using computer generated random number. The sample size for this study was based on an effect size according to Pozehl et al. [17], at 80\% power with a two-tailed significance level of 0.05 and for detecting a standardized effect size $(\Delta=0.47)$ in outcome for the two groups. A total sample size of 30 was obtained for each group. Owing to possible attrition, the sample size was increased to 35 in each group. Ninety-two patients with CHF were invited into the study, however, 12 patients declined participation due to personal reasons while 10 were excluded for not satisfying the inclusion criteria. Consequently, a total number of 70 eligible patients were recruited to accommodate for possible attrition. However, only 63 of the patients completed the eight week programme. Reasons for attrition in both groups included patients' relocation, personal reasons and change in medications were stated in CONSORT (Figure 1).

\subsection{Procedure}

The purpose of the study was explained to the participants before obtaining an informed consent. Socio-demographic information, social history and current medications prescribed by the attending cardiologists were recorded. Anthropometric characteristics were measured using standard procedures. Cardiovascular parameters of resting heart rate, systolic and diastolic blood pressures were measured in sitting position using a validated electronic sphygmomanometer. Participants in EG underwent exercise treadmill test before the commencement of exercise training using the modified Bruce protocol. Participants were encouraged to reach symptom-limited maximal exercise. Age-predicted maximal heart rate was defined as 220 minus age (years).

\subsubsection{Assessment of Physical Function}

Hand Grip Strength Measure: Hand grip strength was assessed with an electronic Camry hand grip dynamometer (Model EH 101) based on the guideline of the American Society of Hand Therapists [18]. Participants squeezed the dynamometer maximally in order to obtain the grip strength reading. Two measurements were taken for each upper extremity with a 2-minutes rest interval; the average was recorded in kilogram-force (Kgf) as grip strength value.

Six-Minute Walk Test (6-MWT): The Six-Minute Walk Test (6-MWT) was performed on a 30 meter level corridor using the American Thoracic Society guidelines [19]. Participants were instructed to walk from the starting point to the end of the corridor at their own selected pace while attempting to cover as much ground as possible in six minutes and the distance covered was recorded. They were encouraged every 30 seconds or more in a standardized manner by saying: "You are doing well" or "Keep up the good work". The functional capacity (Maximum Oxygen Consumption $\left(\mathrm{VO}_{2} \mathrm{max}\right)$ ) of participants was estimated using the predictive equation by the American College of Sport Medicine formulae [20].

Computation: $\mathrm{VO}_{2} \max (\mathrm{mL} \mathrm{O} 2 \mathrm{~kg} / \mathrm{min})=$ Speed $(\mathrm{m} / \mathrm{min}) \times 0.1 \mathrm{~mL} / \mathrm{O}_{2} / \mathrm{kg}+3.5 \mathrm{~mL} / \mathrm{O}_{2} / \mathrm{kg} / \mathrm{min}$.

Activity of Daily Living $(A D L)$ : Multi-Dimensional Health Assessment Questionnaire (MDHAQ) was used to assess Activity of Daily Living (ADL) [21]. The MDHAQ consists of 10 items measuring activities of daily living (ADL) over the last week. The scale is a 4-point Likert-type ranging from "without any difficulty" = 0, "with 
CONSOLIDATED STANDARD FOR REPORTING TRIALS (CONSORT)

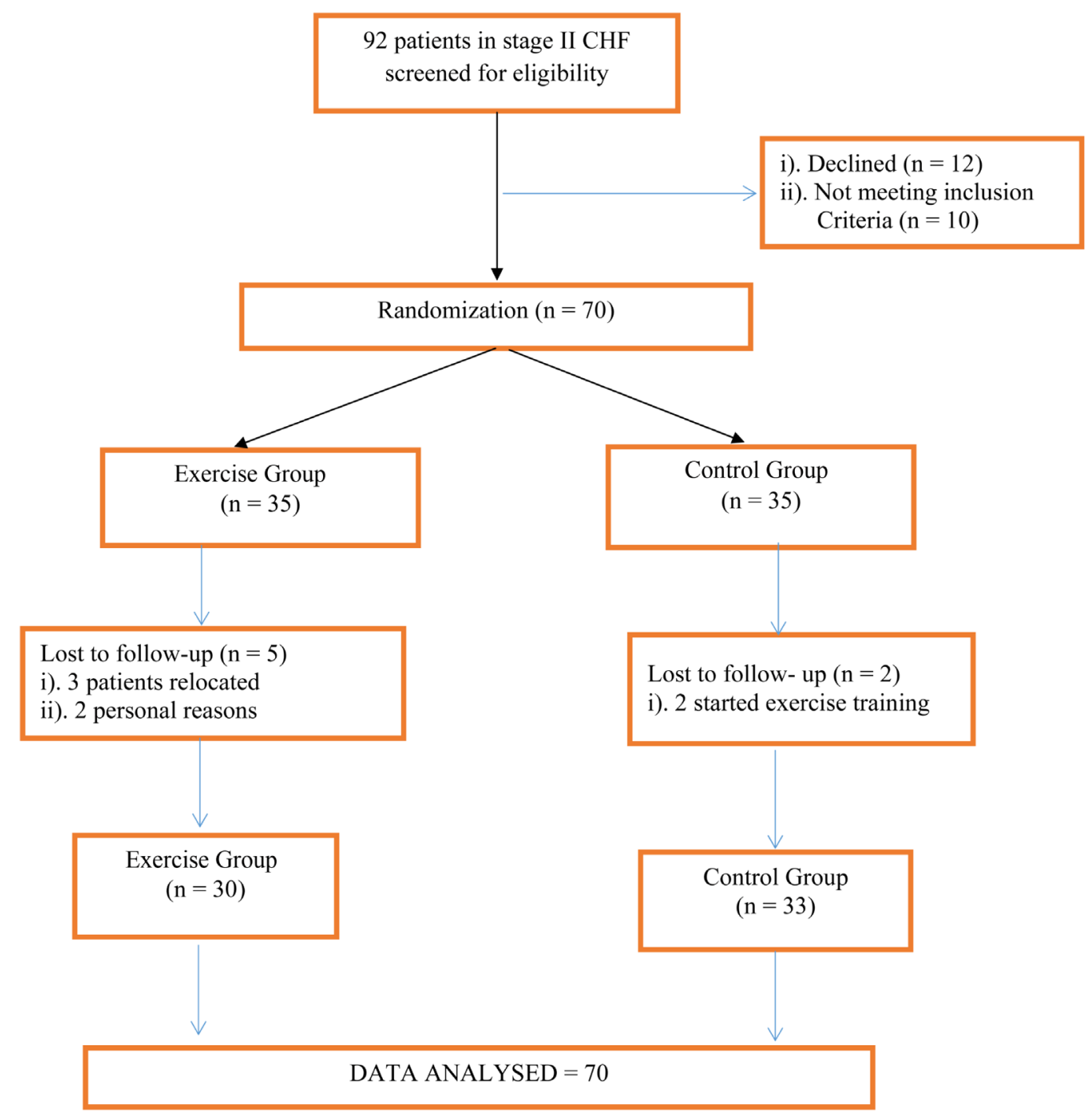

Figure 1. Flowchart for recruitment of patients into the study.

some difficulty" $=1$, "with much difficulty" $=2$ and "unable to do" $=3$. Total score was summed up and transformed thus; $100 \times$ (observed score - minimum possible score)/(maximum possible score - minimum possible score. The higher the score the lesser the activity of daily living.

\subsubsection{Exercise Intervention Protocols}

Parts of the body targeted at improving functions were lower extremity (mobility), upper extremity (dexterity), neck and back function (axial or central). Participants in the EG in addition to pharmacological therapy underwent aerobic and resistance exercises involving self-paced walking, sit to stand exercise, strength training exercise thrice weekly for eight weeks. However, participants in the CG had pharmacological therapy only. Exercise intervention was supervised by (TOA ${ }^{1}$ and $\mathrm{RAA}^{1}$ ). Each participant's training programme was individualized and based on the results of the baseline exercise tests. Exercise intensities, frequency and duration listed in Table 1 and Table 2 served as a guide for exercise prescription

Station 1: Self-paced walking: Participant performed self-paced walking on a 30 meter level corridor for a period of 6 minutes twice per session. During the subsequent weeks, self-paced walking duration was increased progressively by 1 minute on weekly basis. 
Table 1. Aerobic training protocols.

\begin{tabular}{|c|c|c|c|c|c|c|c|c|c|c|}
\hline \multirow{2}{*}{ Week } & \multicolumn{5}{|c|}{ Self-paced walking } & \multicolumn{5}{|c|}{ Sit to stand } \\
\hline & Reps & Set & Freq/week & Duration (min)/set & Intensity (\%) & Reps & Set & Freq/week & Duration (min)/set & Intensity (\%) \\
\hline Week 1 & 1 & 2 & 3 & 6 & $60-65$ & 10 & 2 & 3 & 2 mins $30 \mathrm{~s}$ & $60-65$ \\
\hline Week 2 & 1 & 2 & 3 & 7 & $60-65$ & 10 & 2 & 3 & 2 mins $30 \mathrm{~s}$ & $60-65$ \\
\hline Week 3 & 1 & 2 & 3 & 8 & $60-65$ & 10 & 3 & 3 & 3 mins & $60-65$ \\
\hline Week 4 & 1 & 2 & 3 & 9 & $60-65$ & 10 & 3 & 3 & 3 mins & $60-65$ \\
\hline Week 5 & 1 & 2 & 3 & 10 & $65-70$ & 10 & 4 & 3 & 3 mins $30 \mathrm{~s}$ & $65-70$ \\
\hline Week 6 & 1 & 2 & 3 & 11 & $65-70$ & 10 & 4 & 3 & 3 mins $30 \mathrm{~s}$ & $65-70$ \\
\hline Week 7 & 1 & 2 & 3 & 12 & $65-70$ & 10 & 5 & 3 & 4 mins & $65-70$ \\
\hline Week 8 & 1 & 2 & 3 & 13 & $65-70$ & 10 & 5 & 3 & 4 mins & $65-70$ \\
\hline
\end{tabular}

Key: Reps; repetition, freq; frequency.

Table 2. Strength training protocols for upper extremity.

\begin{tabular}{|c|c|c|c|c|c|c|c|c|c|c|c|c|c|c|c|}
\hline \multirow{2}{*}{ Week } & \multicolumn{5}{|c|}{ Biceps curls } & \multicolumn{5}{|c|}{ Triceps dip } & \multicolumn{5}{|c|}{ Lateral abduction } \\
\hline & Reps & Set & Freq/week & $\begin{array}{l}\text { Duration } \\
\text { (min)/set }\end{array}$ & $\begin{array}{c}\text { Intensity } \\
\text { (\%) }\end{array}$ & Reps & Set & Freq/week & $\begin{array}{l}\text { Duration } \\
\text { (min)/set }\end{array}$ & $\begin{array}{c}\text { Intensity } \\
(\%)\end{array}$ & Reps & Set & Freq/week & $\begin{array}{l}\text { Duration } \\
(\mathrm{min}) / \mathrm{set}\end{array}$ & $\begin{array}{c}\text { Intensity } \\
\text { (\%) }\end{array}$ \\
\hline Week 1 & 10 & 2 & 3 & $1 \min 30 \mathrm{~s}$ & $60-65$ & 10 & 2 & 3 & $1 \mathrm{~min} 30 \mathrm{~s}$ & $60-65$ & 10 & 2 & 3 & $1 \min 30 \mathrm{~s}$ & $60-65$ \\
\hline Week 2 & 10 & 2 & 3 & $1 \mathrm{~min} 30 \mathrm{~s}$ & $60-65$ & 10 & 2 & 3 & $1 \mathrm{~min} 30 \mathrm{~s}$ & $60-65$ & 10 & 2 & 3 & $1 \mathrm{~min} 30 \mathrm{~s}$ & $60-65$ \\
\hline Week 3 & 12 & 2 & 3 & 2 mins & $60-65$ & 12 & 2 & 3 & 2 mins & $60-65$ & 12 & 2 & 3 & 2 mins & $60-65$ \\
\hline Week 4 & 12 & 2 & 3 & 2 mins & $60-65$ & 12 & 2 & 3 & 2 mins & $60-65$ & 12 & 2 & 3 & 2 mins & $60-65$ \\
\hline Week 5 & 14 & 2 & 3 & $2 \min 30 s$ & $65-70$ & 14 & 2 & 3 & $2 \min 30 s$ & $65-70$ & 14 & 2 & 3 & $2 \min 30 s$ & $65-70$ \\
\hline Week 6 & 14 & 2 & 3 & $2 \min 30 s$ & $65-70$ & 14 & 2 & 3 & $2 \min 30 s$ & $65-70$ & 14 & 2 & 3 & $2 \min 30 s$ & $65-70$ \\
\hline Week 7 & 16 & 2 & 3 & 4 mins & $65-70$ & 15 & 2 & 3 & 4 mins & $65-70$ & 15 & 2 & 3 & 4 mins & $65-70$ \\
\hline Week 8 & 16 & 2 & 3 & 4 mins & $65-70$ & 15 & 2 & 3 & 4 mins & $65-70$ & 15 & 2 & 3 & 4 mins & $65-70$ \\
\hline
\end{tabular}

Key: Reps; Repetition, Freq; Frequency, wk: week.

Station 2: Sit to stand exercise: Participant sat on a straight-back and armless chair of standard height [22]. Participant then stood up from sitting to standing position and return to sitting immediately [23]. Ten (10) consecutive movements were performed with two (2) sets per session. Progressively, one new set was added at 2-week interval (i.e. 2nd, 4th and 8th week) (Table 1).

Station 3: Bicep curls, Triceps dips and Lateral abduction: One Repetition Maximum (1RM) was determined at the onset for strength training. This is the maximum amount of weight $(\mathrm{Kg})$ one can lift in a single repetition of maximal contraction [24]. During the first two weeks, a total of 10 repetitions of biceps curls were performed at $75 \%$ of $1 \mathrm{RM}$ for each upper limb. Ten repetition of triceps dip were performed in the direction of shoulder joint extension with elbow joint in full extension. Furthermore, ten repetitions of lateral abduction were performed which included shoulder joint abduction to $90^{\circ}$ and full extension of elbow joint [25]. Progressively, two new repetitions were added at 2-week interval (i.e. 2nd, 4th and 8th week) (Table 2). To ensure overload, 1 RM was re-determined at 2-weeks interval using 75\% of new 1RM. The 10-point Modified Borg Scale was used to monitor rate of perceived exertion and a polar heart rate monitor was used to observe heart rate response to exercise.

Exercise training was preceded by 10 minutes of warm-up and ended with 10 minutes cold-down. Total exercise duration at onset was 30 minutes and progressively increased to 60 minutes per session by the 8th week. Frequency of exercise was thrice weekly and exercise intensity ranged between $60 \%-70 \%$ of maximal heart 
rate. Although, no adverse event was recorded during the course of the study, resuscitation materials were made available in case of emergency. Treatment outcomes were assessed at 4th and 8th by an assessor who was blinded to treatment groups. Participants in the CG were given lectures on personal hygiene and reminders on medications but no instruction on exercise.

Study adherence: The adherence to appointment was computed for both experimental and control groups. For the experimental group, the number of sessions attended was divided by the maximum of sessions possible (24) and multiplied by 100 . The participants in the control group were coming every two week after the baseline measurements. The number of visits during the intervention period was four. So, the number of visits made was divided by four and multiplied by 100 which constituted the adherence rate [26]. Participants were called on phone to remind them of the appointment.

\subsection{Statistical Analyses}

Descriptive statistics was used to summarize anthropometric and socio-demographic characteristics. Independent t-test was used to compare exercise and control groups at baseline. Furthermore, Independent t-test was also used to compare the baseline physical characteristics, physical function variables and cardiovascular parameters between exercise and control groups. Two-way Analysis of Variance (ANOVA) (time period by intervention) was used to compare the effects of exercise intervention on ADL, right and left HGS, 6MWD and estimated $\mathrm{VO}_{2}$ max at fourth and eighth week between exercise and control groups. Bonferroni post hoc analysis was used to probe the direction of significance. Data for those who did not complete the study was treated as intention to treat analysis. STATA-SE version 11.0 (STATA Corp LP, Texas, USA) of Windows Software was used to carry out statistical analysis. Alpha level was set at $p<0.05$ of significance.

\section{Results}

Socio-demographic characteristics and clinical profile of all participants were presented in Table 3. The mean age of the participants in EG and CG were $68.9 \pm 6.5$ and $64.3 \pm 12.3$ years respectively. Comparison of physical characteristics and cardiovascular parameters of all participants at baseline were comparable except WHR ( $p$ $<0.05$ ) (Table 4). Similarly, comparison of physical function variables of all participants were comparable at baseline (Table 5). At fourth week, participants in EG showed significant improvements in ADL (30.0 $\pm 6.0 \%$ ),

Table 3. Socio-demographic and clinical characteristics of participants in experimental and control group.

\begin{tabular}{ccc}
\hline Variable & Exercise $(\mathrm{n}=35)$ & $\mathrm{Control}(\mathrm{n}=35)$ \\
\hline Gender & $\mathrm{n}(\%)$ & $14(40.0)$ \\
Male & $18(51.4)$ & $21(60.0)$ \\
Female & $17(48.6)$ & $26(74.3)$ \\
Aetiology & & $2(5.7)$ \\
Hypertensive Heart Disease & $24(68.6)$ & $3(8.6)$ \\
Rheumatic Heart Disease & $4(11.4)$ & $2(5.7)$ \\
Ischaemic Heart Disease & $2(5.7)$ & $2(5.7)$ \\
Valvular Heart Disease & $3(8.6)$ & $24(72.7)$ \\
Idiopathic Cardiomyopathy & $2(5.7)$ & $6(18.2)$ \\
Current Medication & & $3(9.1)$ \\
ACE-I/ARB/Digoxin & $20(66.7)$ & $6(20.0)$ \\
Beta Blocker/Digoxin & $4(13.3)$ & \\
Diuretics/Spironolactone & & \\
\hline
\end{tabular}

Key: ACE-I, Angiotensin Converting Enzyme-Inhibitor; ARB, Angiotensin II Receptor Blocker. 
Table 4. Physical characteristics and cardiovascular parameters of participants.

\begin{tabular}{|c|c|c|c|c|}
\hline \multirow{2}{*}{ Variable } & Exercise Group (n = 35) & Control Group $(\mathrm{n}=35)$ & \multirow{2}{*}{$\mathrm{t}$-cal. } & \multirow{2}{*}{ p-value } \\
\hline & Mean \pm S.D & Mean \pm S.D & & \\
\hline Age (years) & $68.9 \pm 6.5$ & $64.3 \pm 12.3$ & 1.32 & 0.197 \\
\hline Height (m) & $1.7 \pm 0.1$ & $1.6 \pm 0.1$ & 0.56 & 0.577 \\
\hline Weight (kg) & $66.0 \pm 12.2$ & $65.3 \pm 15.5$ & 0.31 & 0.758 \\
\hline $\operatorname{BMI}\left(\mathrm{kg} / \mathrm{m}^{2}\right)$ & $24.2 \pm 4.7$ & $23.8 \pm 5.2$ & 0.22 & 0.829 \\
\hline WHR & $0.8 \pm 0.1$ & $0.9 \pm 0.1$ & -3.23 & $0.003^{*}$ \\
\hline SBP (mmHg) & $137.3 \pm 17.2$ & $136.8 \pm 12.4$ & 0.55 & 0.243 \\
\hline DBP (mmHg) & $84.9 \pm 6.3$ & $85.1 \pm 2.1$ & 0.32 & 0.980 \\
\hline RHR (beat/min) & $83.7 \pm 6.2$ & $83.0 \pm 4.9$ & 0.28 & 0.640 \\
\hline
\end{tabular}

${ }^{*} p$ < 0.05. Key: BMI: Body Mass Index; WHR: Waist to Hip Ratio; Systolic Blood Pressure; DBP: Diastolic Blood Pressure; RHR: Resting Heart Rate.

Table 5. Baseline comparison of physical function variables between exercise and control groups.

\begin{tabular}{cccccc}
\hline & Exercise Group $(\mathrm{n}=35)$ & Control Group $(\mathrm{n}=35)$ & & t-cal. & p-value \\
\cline { 2 - 4 } Variable & Mean \pm S.D & Mean \pm S.D & & 0.412 & 0.683 \\
ADL (\%) & $45.0 \pm 10.0$ & $45.0 \pm 9.5$ & $25.1 \pm 4.3$ & 1.330 & 0.193 \\
HGS-R (Kgf) & $27.4 \pm 5.3$ & $21.8 \pm 4.8$ & 0.432 & 0.669 \\
HGS-L (Kgf) & $22.6 \pm 5.6$ & $309.2 \pm 27.8$ & -0.161 & 0.873 \\
6-MWD (m) & $307.7 \pm 22.5$ & $8.6 \pm 0.5$ & -0.161 & 0.873 \\
\hline
\end{tabular}

Keys: ADL, Activity of daily Living; HGS-R, Right hand grip strength; HGS-L, Left hand grip strength; 6-MWD, 6-Minute walk distance; Est.VO Max, Estimated maximum oxygen consumption.

6MWD (321.7 $\pm 26.3 \mathrm{~m})$ and $\mathrm{VO}_{2} \max (8.9 \pm 0.4 \mathrm{~mL} / \mathrm{kg} / \mathrm{min})(p<0.05)$ but no significant changes was observed in the CG $(p>0.05)$. Furthermore, participants in EG demonstrated significant improvements in ADL $(15.0 \% \pm 5.0 \%), 6 \mathrm{MWD}(406.0 \pm 29.7 \mathrm{~m})$ and $\mathrm{VO}_{2} \max (10.3 \pm 0.5 \mathrm{~mL} / \mathrm{kg} / \mathrm{min})(p<0.05)$ than participants in CG: ADL $(42.0 \% \pm 5.0 \%), 6 \mathrm{MWD}(321.0 \pm 25.7 \mathrm{~m})$ and $\mathrm{VO}_{2} \max (8.9 \pm 0.4 \mathrm{~mL} / \mathrm{kg} / \mathrm{min})$ at eighth $(p>0.05)$ at eighth $(p>0.05)$. There was no significant improvement in both right and left HGS in both groups at fourth and eighth weeks of the study $(p>0.05)$ (Table 6).

\section{Discussion}

This study investigated the effects self-paced walk exercise, sit to stand exercise and upper extremity resistance training on physical function in patients with stable CHF. The results showed that significant improvement was recorded in the activity of daily living (ADL) following exercise intervention. Our finding is in agreement with previous studies that exercise is capable of restoring functional activity of daily living of patients with chronic diseases [7] [11]. The improvement in ADL could be attributed to an increase in muscular strength and aerobic capacity following exercise training. Exercise has been reported to be useful in reversing pathological changes in CHF by improving muscular strength of atrophied muscles, increasing capillary density and mitochondria content or oxidative enzymes activity [10] [27]. Change in physiologic profile of patients with chronic illnesses often translate to significant increase in ADL such as personal self-care including bathing, dressing and feeding which are the basic building components of physical function.

Findings from our study show that the distance walked in 6 minute (6-MWD) in the exercise group improved significantly post intervention. In agreement with previous studies, exercise in CHF has been reported to lead to 
Table 6. Two-way ANOVA (repeated measures) and Bonferroni post hoc comparison of physical function variables between experimental and control groups.

\begin{tabular}{cccccccc} 
& \multicolumn{2}{c}{ Exercise Group $(\mathrm{n}=35)$} & \multicolumn{2}{c}{ Control Group ( $\mathrm{n}=35)$} & & \\
\cline { 2 - 5 } Variable & Week 4 & Week 8 & Week 4 & Week 8 & & F & p-value \\
\cline { 2 - 5 } & Mean \pm S.D & Mean \pm S.D & Mean \pm S.D & Mean \pm S.D & & \\
ADL (\%) & $30.0 \pm 6.0^{\mathrm{a}}$ & $15.0 \pm 5.0^{\mathrm{b}}$ & $45.0 \pm 9.0^{\mathrm{c}}$ & $42.0 \pm 5.0^{\mathrm{c}}$ & 310.70 & $0.001^{*}$ \\
HGS-R (Kgf) & $27.7 \pm 5.1$ & $28.4 \pm 5.3$ & $25.3 \pm 4.2$ & $25.2 \pm 4.1$ & 1.91 & 0.129 \\
HGS-L (Kgf) & $22.6 \pm 5.5$ & $22.8 \pm 5.8$ & $22.0 \pm 4.8$ & $22.1 \pm 4.8$ & 0.13 & 0.966 \\
6-MWD (m) & $321.7 \pm 26.3^{\mathrm{a}}$ & $406.0 \pm 29.7^{\mathrm{b}}$ & $315.8 \pm 24.6^{\mathrm{c}}$ & $321.0 \pm 25.7^{\mathrm{a}}$ & 41.54 & $0.001^{*}$ \\
Estimated VO VO $_{2}$ Max (mL/kg/min) & $8.9 \pm 0.4^{\mathrm{a}}$ & $10.3 \pm 0.5^{\mathrm{b}}$ & $8.8 \pm 0.4^{\mathrm{a}}$ & $8.9 \pm 0.4^{\mathrm{a}}$ & 41.54 & $0.001^{*}$ \\
\hline
\end{tabular}

${ }^{*} p<0.05$. Superscripts $\left({ }^{\mathrm{a}, \mathrm{b}, \mathrm{c}}\right)$ Superscripts with the same alphabets are not significant while those with different alphabets are significant. For example, the four column comparison of mean of ADL showed a significant difference between EG at week 4 and 8 as indicated by superscript with different alphabets $\left({ }^{a, b}\right)$, likewise, mean mode in EG at week 4 and 8 was significantly different compared with CG at week 4 and 8 with superscript ${ }^{c}$ while there was no significant difference in CG at week 4 and 8 as indicated by same superscript ${ }^{c}$. Keys: ADL, Activity of daily living; HGS-R, Right hand grip strength; 6MWD, 6-Minute Walk Distance; HGS-L, Left hand grip strength; Est. $\mathrm{VO}_{2}$ Max, Estimated maximum oxygen consumption.

substantial gain in distance walked after training [11] [27]. Significant increase in 6-MWD may be as a result of regular muscular activity during self-paced walking which in turn translates to improved physical performance. It is not surprising to observe significant improvement in the functional capacity $\left(\mathrm{VO}_{2}\right.$ max) in our study. Walking as component of daily activity, if properly implemented, improves aerobic performance and oxygen utilization in both patients and healthy population [28].

Our study observed a total gain of $98.3 \mathrm{~m}$ in distance covered which was higher than the one reported in previous studies by Owen and Croucher [16] and Gottlieb et al. [29]. The distance walk gained and subsequent improvement in the estimated maximum oxygen consumption $\left(\mathrm{VO}_{2} \max \right)$ in our study might have been influenced by functional exercise regimens that mimic activity of daily living with resultant improvement in aerobic performance. However, contrast to our findings, McKelvie et al. [30] reported no significant improvement in the 6-MWD between exercise and control groups among patients with CHF. The non-significant difference could be linked to lack of exercise supervision and poor adherence among study participants.

Adherence to exercise programme is a challenge in rehabilitation care [31] [32]. However, adherence to treatment in our study was enhanced by regular cell phone calls to remind the participants about appointment. Besides simplicity of the exercise designs which gave participants the opportunity to engage in regular exercise practice without much supervision, regular phone calls appear to contribute to consistent hospital appointments and compliance with prescribed exercise programmes. Our exercise interventions were designed to incorporate task and context specific practice that are meaningful to patients' activity of daily living with an overall goal of functional independence and treatment adherence.

Specifically, our study adopted the PROMIS protocols which emphasized mobility (lower extremity), dexterity (upper extremity), axial or central (neck and back function) and complex activities involving more than one subdomain [15]. These simple activities such as upper extremity resistance training using dumbbells, aerobic exercise including sit to stand and self-paced walking exercises are safe and are considered basic functional activities for improving mobility, transferring and grasping in rehabilitation care. This implies that functional exercises as described in our study may help patients with CHF to benefit from simple exercise programmes especially in resource poor nations where cardiac rehabilitation equipment are limited [33] [34].

Despite widely reported benefits of exercise training in CHF, its adoption is still being underutilized worldwide [34]. Factors such as cost of exercise devices owing to economic challenges, lack of expertise and skepticism about exercise safety among health workers in low and middle income countries could be some of the reasons for low utilization. Similarly, in sub-Sahara Africa (SSA), exercise training as an important component of rehabilitation has not been incorporated for CHF care owing to low referral rate from physicians. There is an urgent need to integrate simple and safe functional exercise programme as part of rehabilitation care plan with the view to reducing cardiovascular disability and mortality among patients with CHF in SSA. Findings from this study should be interpreted with caution due to some inherent limitations. Patients in both groups were placed on different antihypertensive and other medications with varying dosages which may cause patients to 
respond differently to treatment. Furthermore, baseline physical activity of these patients was not assessed prior commencement of this study. More importantly, patients in our study might be involved in some physical activity which were covert and not monitored during the course of this study. In addition, assessment of ADL in this study was assessed using a self-reported method which is prone to estimation error and recall bias.

\section{Conclusions}

Supervised exercise training protocols involving self-paced walking, sit-to-stand and upper extremity dynamic strength training improved physical function including activity of daily living, walking and functional capacities in patients with stable chronic heart failure. Exercise intervention protocols that are safe and simple, mimicking functional activities and well tolerated among patients with stable chronic heart failure may enhance exercise adherence.

\section{Acknowledgements}

The authors wish to thank the Consortium for Advanced Research Training in Africa (CARTA) for providing technical support. CARTA is jointly led by the African Population and Health Research Center and the University of the Witwatersrand and funded by the Wellcome Trust (UK) (Grant No: 087547/Z/08/Z), the Department for International Development (DfID) under the Development Partnerships in Higher Education (DelPHE), the Carnegie Corporation of New York (Grant No: B 8606), the Ford Foundation (Grant No: 1100-0399), Swedish International Development Corporation Agency—SIDA (grant: 54100029), Google.Org (Grant No: 191994), and MacArthur Foundation Grant No: 10-95915-000-INP.

\section{Ethical Approval}

The study protocol was approved by the Ethics and Research Committee (ERC/2012/08/04), Obafemi Awolowo University Teaching Hospitals Complex, Ile-Ife, Nigeria.

\section{Presentation}

Abstract of this study was presented at the Scientific Symposium for Emerging Scholars in Health organized by the African Population and Health Research Centre (APHRC), Hilton Hotel, Nairobi, Kenya, July 15-17, 2013.

\section{Conflict of Interest}

The author declares that they have no conflict of interest.

\section{References}

[1] Lloyd-Jones, D., Adams, R.J., Brown, T.M., Carnethon, M., Dai De, S. and Simone, G. (2010) On Behalf of the American Heart Association Statistics Committee and Stroke Statistics Subcommittee. Heart Disease and Stroke Statistics-2010 Update. A Report from the American Heart Association. Circulation, 121, e1-170.

[2] Bleumink, G.S., Knetsch, A.M., Sturkenboom, M.C., Straus, S.M., Hofman, A. and Deckers, J.W. (2004) Quantifying the Heart Failure Epidemic: Prevalence, Incidence Rate, Lifetime Risk and Prognosis of Heart Failure. The Rotterdam Study. European Heart Journal, 25, 1614-1619. http://dx.doi.org/10.1016/j.ehj.2004.06.038

[3] Kingue, S., Dzudie, A., Menanga, A., Akono, M., Ouankou, M. and Muna, W. (2005) A New Look at Adult Chronic Heart Failure in Africa in the Age of the Doppler Echocardiography: Experience of the Medicine Department at Yaounde General Hospital. Annales de Cardiologie et d Angéiologie (Paris), 54, 276-283. http://dx.doi.org/10.1016/j.ancard.2005.04.014

[4] Adedoyin, R.A. and Adesoye, A.T. (2005) Incidence and Pattern of Cardiovascular Diseases in a Nigerian Hospital. Tropical Doctor, 35, 104-106.

[5] Ojji, D.B., Alfa, J., Ajayi, S.O., Mamven, M.H. and Falase, A.O. (2009) Pattern of Heart Failure in Abuja, Nigeria: An Echocardiographic Study. Cardiovascular Journal of Africa, 20, 349-352.

[6] Damasceno, A., Cotter, G., Dzudie, A., Sliwa, K. and Mayosi, B.M. (2007) Heart Failure in Sub-Saharan Africa: Time for Action. Journal of the American College of Cardiology, 50, 1688-1693. http://dx.doi.org/10.1016/j.jacc.2007.07.030

[7] Rees, K., Taylor, R.S., Singh, S., Coats, A.J. and Ebrahim, S. (2004) Exercise Based Rehabilitation for Heart Failure 
(Cochrane Review). In: The Cochrane Library, John Wiley, Chichester, 3.

[8] Boxer, R.S., Wang, Z., Walsh, S.J., Hager, D. and Kenny, A.M. (2008) The Utility of the 6-Minute Walk Test as a Measure of Frailty in Older Adults with Heart Failure. The American Journal of Geriatric Cardiology, 17, 7-12. http://dx.doi.org/10.1111/j.1076-7460.2007.06457.x

[9] Ajiboye, O.A., Anigbogu, C.N., Ajuluchukwu, J.N. and Jaja, S.I. (2014) Exercise Training Improves Functional Walking Capacity and Activity Level of Nigerians with Chronic Biventricular Heart Failure. Hong Kong Physiotherapy, 33, 42-49. http://dx.doi.org/10.1016/j.hkpj.2014.11.002

[10] O’Connor, C.M., Whellan, D.J., Lee, K.L., Keteyian, S.J., Cooper, L.S. and Ellis, S.J. (2009) Efficacy and Safety of Exercise Training in Patients with Chronic Heart Failure: HF-ACTION Randomized Controlled Trial. JAMA, 301, 1439-1450. http://dx.doi.org/10.1001/jama.2009.454

[11] Lloyd-Williams, F., Mair, F.S. and Leitner, M. (2002) Exercise Training and Heart Failure: A Systematic Review of the Current Evidence. British Journal of General Practice, 52, 47-55.

[12] Piña, I.L., Apstein, C.S., Balady, G.J., Belardinelli, R., Chaitman, B.R., Duscha, B.D., et al. (2003) Exercise and Heart Failure: A Statement from the American Heart Association Committee on Exercise, Rehabilitation, and Prevention. Circulation, 107, 1210-1225. http://dx.doi.org/10.1161/01.CIR.0000055013.92097.40

[13] Cella, D., Yount, S., Rothrock, N., Gershon, R., Cook, K., Reeve, B., et al. (2007) The Patient Reported Outcomes Measurement Information System (PROMIS): Progress of an NIH Roadmap Cooperative Group during Its First Two Years. Medical Care, 45, 3-11. http://dx.doi.org/10.1097/01.mlr.0000258615.42478.55

[14] Berg-Emons, van den H.J.G., Bussmann, J., Balk, A., Keijzer-Oster, D. and Stam, H. (2001) Level of Activities Associated with Mobility during Everyday Life in Patients with Chronic Congestive Heart Failure as Measured with an Activity Monitor. Physical Therapy, 81, 1502-1511.

[15] Thompson, P.D. (2005) Exercise Prescription and Proscription for Patients with Coronary Artery Disease. Circulation, 112, 2354-2363. http://dx.doi.org/10.1161/CIRCULATIONAHA.104.502591

[16] Owen, A. and Croucher, L. (2000) Effect of an Exercise Programme for Elderly Patients with Heart Failure. European Journal of Heart Failure, 2, 65-70. http://dx.doi.org/10.1016/S1388-9842(99)00067-7

[17] Pozehl, B., Duncan, K., Hertzog, M. and Norman, J.F. (2010) Heart Failure Exercise and Training Camp: Effects of a Multicomponent Exercise Training Intervention in Patients with Heart Failure. Heart Lung, 39, S1-S13. http://dx.doi.org/10.1016/j.hrtlng.2010.04.008

[18] American Society of Hand Therapists (ASHT Editor) (1981) Clinical Assessment Recommendations. Garner, NC.

[19] American Thoracic Society (ATS) Statement (2000) Guidelines for the Six-Minute Walk Test. American Journal of Respiratory and Critical Care Medicine, 166, 111-117.

[20] American College of Sport Medicine (ACSM) (1995) Prediction of Maximum Oxygen Consumption $\mathrm{VO}_{2} \mathrm{Max}_{\text {during }}$ Level Walking.

[21] Pincus, T., Sokka, T. and Kautiainen, H. (2005) Further Development of a Physical Function Scale on a Multidimensional Health Assessment Questionnaire for Standard Care of Patients with Rheumatic Diseases. Journal of Rheumatology, 32, 1432-1439.

[22] Miller, J. (2009) Chairs. Conran, Mannheim, Deutschland.

[23] Canning, C.G., Shepherd, R.B., Carr, J.H., Alison, J.A., Wade, L. and White, A. (2003) A Randomized Controlled Trial of the Effects of Intensive Sit-to-Stand Training after Recent Traumatic Brain Injury on Sit-to-Stand Performance. Clinical Rehabilitation, 17, 355-362. http://dx.doi.org/10.1191/0269215503cr620oa

[24] Hetherington, N. (2005) How to Assess Your One Repetition Maximum (1RM) for Strength Training. In: Brian Mackenzie's Successful Coaching, 2nd Edition, Electric Word Plc., 10-11.

[25] Pollock, M.L., Franklin, B.A., Balady, G.J., Chaitman, B.L., Fleg, J.L., Fletcher, B., et al. (2000) Resistance Exercise in Individuals with and without Cardiovascular Disease: Benefits, Rationale, Safety, and Prescription: An Advisory from the Committee on Exercise, Rehabilitation, and Prevention, Council on Clinical Cardiology. American Heart Association, Position Paper Endorsed by the American College of Sports Medicine, AHA Science Advisory, Circulation, 101, 828-833. http://dx.doi.org/10.1161/01.cir.101.7.828

[26] Maruf, F.A., Akinpelu, A.O. and Salako, B.L (2013) Self-Reported Quality of Life before and after Aerobic Exercise Training in Individuals with Hypertension: A Randomized-Controlled Trial. Applied Psychology: Health and WellBeing, 5, 209-224. http://dx.doi.org/10.1111/aphw.12005

[27] Kiilavuori, K., Naveri, H., Salmi, T. and Harkonen, M. (2000) The Effect of Physical Training on Skeletal Muscle in Patients with Chronic Heart Failure. European Journal of Heart Failure, 2, 53-63. http://dx.doi.org/10.1016/S1388-9842(00)00058-1

[28] Hulsmann, M., Quittan, M. and Berger, R. (2004) Muscle Strength as a Predictor of Long Term Survival in Severe 
Congestive Heart Failure. European Journal of Heart Failure, 6, 101-107. http://dx.doi.org/10.1016/j.ejheart.2003.07.008

[29] Gottlieb, S.S., Fisher, M.L. and Freudenberger, R. (1999) Effects of Exercise Training on Peak Performance and Quality of Life in Congestive Heart Failure Patients. Journal of Cardiac Failure, 5, 188-194. http://dx.doi.org/10.1016/S1071-9164(99)90002-7

[30] McKelvie, R.S. (2003) Heart Failure. Clinical Evidence, 9, 95-118.

[31] Jackson, L., Leclerc, J., Erskine, Y. and Linden, W. (2005) Getting the Most out of Cardiac Rehabilitation: A Review of Referral and Adherence Predictors. Heart (British Cardiac Society), 91, 10-14. http://dx.doi.org/10.1136/hrt.2004.045559

[32] Jack, K. McLean, S.M., Moffett, J.K. and Gardinerc, E. (2010) Barriers to Treatment Adherence in Physiotherapy Outpatient Clinics: A Systematic Review. Manual Therapy, 15, 220-228. http://dx.doi.org/10.1016/j.math.2009.12.004

[33] Adedoyin, R.A., Adeyanju, S.A., Balogun, M.O., Akintomide, A.O., Adebayo, R.A., Akinwusi, P.O., et al. (2010) Assessment of Exercise Capacity in African Patients with Chronic Heart Failure Using Six Minute-Walk. International Journal of General Medicine, 3, 109-113. http://dx.doi.org/10.2147/IJGM.S5533

[34] Mampuya, W.M. (2012) Cardiac Rehabilitation Past, Present and Future: An Overview. Cardiovascular Diagnosis and Therapy, 2, 38-49.

\section{Submit or recommend next manuscript to SCIRP and we will provide best service for you:}

Accepting pre-submission inquiries through Email, Facebook, LinkedIn, Twitter, etc.

A wide selection of journals (inclusive of 9 subjects, more than 200 journals)

Providing 24-hour high-quality service

User-friendly online submission system

Fair and swift peer-review system

Efficient typesetting and proofreading procedure

Display of the result of downloads and visits, as well as the number of cited articles

Maximum dissemination of your research work

Submit your manuscript at: http://papersubmission.scirp.org/ 